\title{
Coral Microbial Ecology
}

\section{INTRODUCTION}

Coral microbial ecology is the study of the relationship of coral-associated microorganisms to each other, the coral host, and to their environment. Just as we humans have beneficial bacteria living on our skin and in our intestines, corals also have co-habitating non-pathogenic (not disease-causing) microbes. These microbes include bacteria, archaea, and fungirepresenting all three of the major domains of life (Fig. 1). Archaea are prokaryotes (cells with no nucleus) like bacteria but are genetically and biochemically more similar to eukaryotes (organisms with cells that contain a true nucleus).

Where are these microbes? Coral-associated microorganisms are found in the mucus, tissue, and skeleton of corals. Corals secrete a surface layer of mucus, which functions to keep the coral surface clean of sediment and to capture prey. Each species of coral has mucus that is biochemically unique. When shed, this mucus provides a major nutrient source for the reef environment (Wild, 2004). The tissue of the coral animal is where the symbiotic algae, known as zooxanthellae, live. Endolithic microorganisms (bacteria, fungi, or algae that bore into the coral's calcium carbonate skeleton) are a potential source of nutrients to the overlying tissues.

What can we learn from studying coral microbial ecology? Why is it important? Coral reefs in the Caribbean have been in decline for several decades. One of the most visible causes is disease. Coral diseases are not well understood, but the few that have been characterized are all caused by microorganisms. In order to understand the diseased state, we must first understand the healthy state. Until now, coral biology studies have been limited to studies of the coral animal, the algal symbiont, or the interactions of the two. Coral microbial-ecology studies contribute a missing piece of information to the study of overall coral biology. It has been speculated that coral-associated bacteria benefit the coral by fixing nitrogen, breaking down waste products, and cycling basic nutrients back to the photosynthetic algal symbionts (zooxanthellae). Bacteria may also ward off other potentially harmful microbes by producing antibiotics or by just occupying the available space. Relative to disease studies, it would be helpful to know if the infectious agents come from the normal microbial flora under certain conditions.

The field of coral microbial ecology is relatively new. What do we know so far?

- A handful of coral pathogens (microbes that are proven to cause a specific disease) have been identified (reviewed by Rosenberg and Loya, 2004).

- Coral-associated microbes are distinct from those in the water column (FriasLopez, 2002).

- Different species of corals have different bacterial communities (Rohwer, 2002).

- The coral-associated bacterial community shifts when the coral is stressed (Pantos, 2003).

\section{USGS CORAL MICROBIAL-ECOLOGY STUDIES}

The U.S. Geological Survey (USGS) scientists involved in each study are listed in brackets after the project titles.

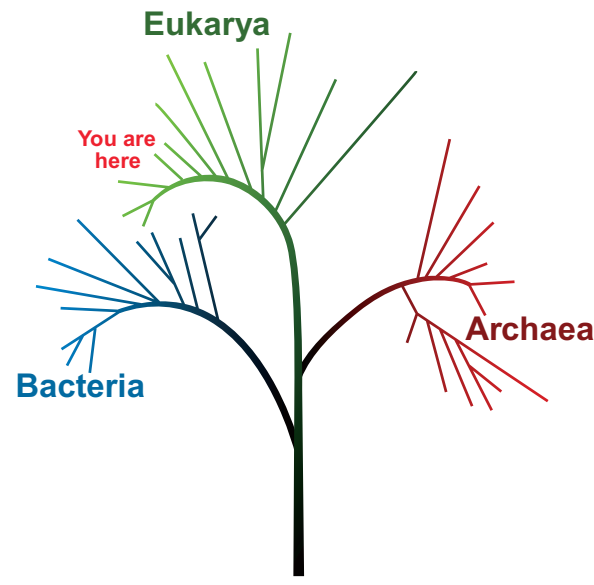

Figure 1. The molecular "Tree of Life" consists of three domains derived from $16 \mathrm{~S}$ rDNA genetic data. $16 \mathrm{~S} r \mathrm{DNA}$ is the gene that codes for ribosomal RNA, a key part of cellular reproduction. Eukarya includes plants, animals, and fungi.

\section{Global Climate Change - Microbial Communities as a Diagnostic Tool? [Christina Kellogg, Virginia Garrison, John Lisle]}

Scientists and reef managers are concerned about coral reef systems being affected by global change and need to understand the processes that control their resilience. This large, integrated project involves collaboration between the USGS, the

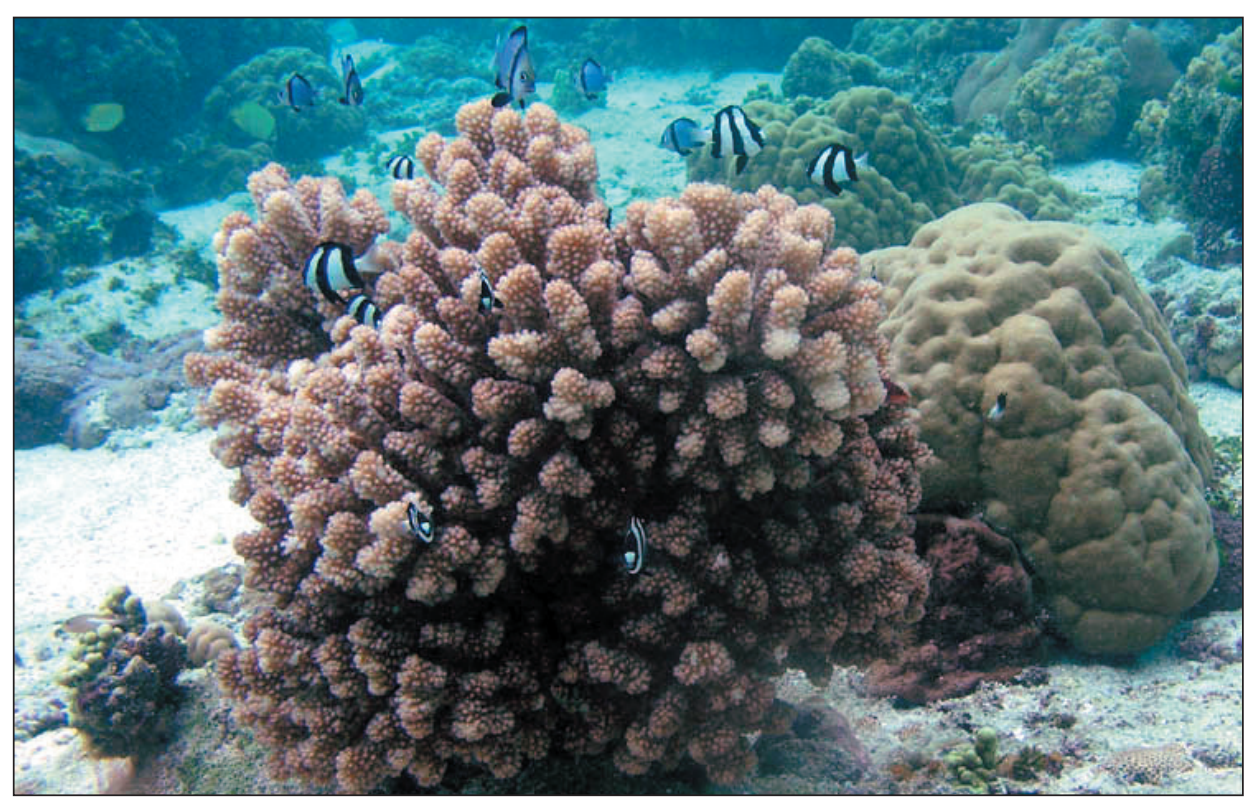

Figure 2. Pocillopora eydouxi is one of the coral species being monitored for microbial-community changes in Ofu Lagoon, American Samoa. Photo credit: Virginia Garrison, USGS. 
University of Hawaii, the Florida Institute of Technology, the Wildlife Conservation Society, and the National Park Service. Studies are underway in the National Park of American Samoa to determine the internal and external factors that increase the ability of a wide variety of corals to resist environmental stress. The shallow lagoon there contains species of Acropora and Pocillopora, corals ordinarily prone to bleaching (expelling their symbionts) at high temperatures (Fig. 2). External factors include changes in water temperature, ultraviolet (UV) radiation, dissolved oxygen, and water motion. Internal factors being investigated include genetic diversity of algal symbionts and the associated microbial communities. Because changes in the coral-associated bacterial communities echo changes in the health of the coral, bacteria are at minimum atuned to their host's metabolism and may play an active role in maintaining the overall health of the coral.

The microbial-ecology portion of this project seeks to answer the following questions: (1) Does the coral-associated bacterial community shift on a seasonal basis? We are using molecular methods to analyze and compare "fingerprints" of the total bacterial community quarterly for one year.

(2) If the microbial community does change, do the changes correlate to

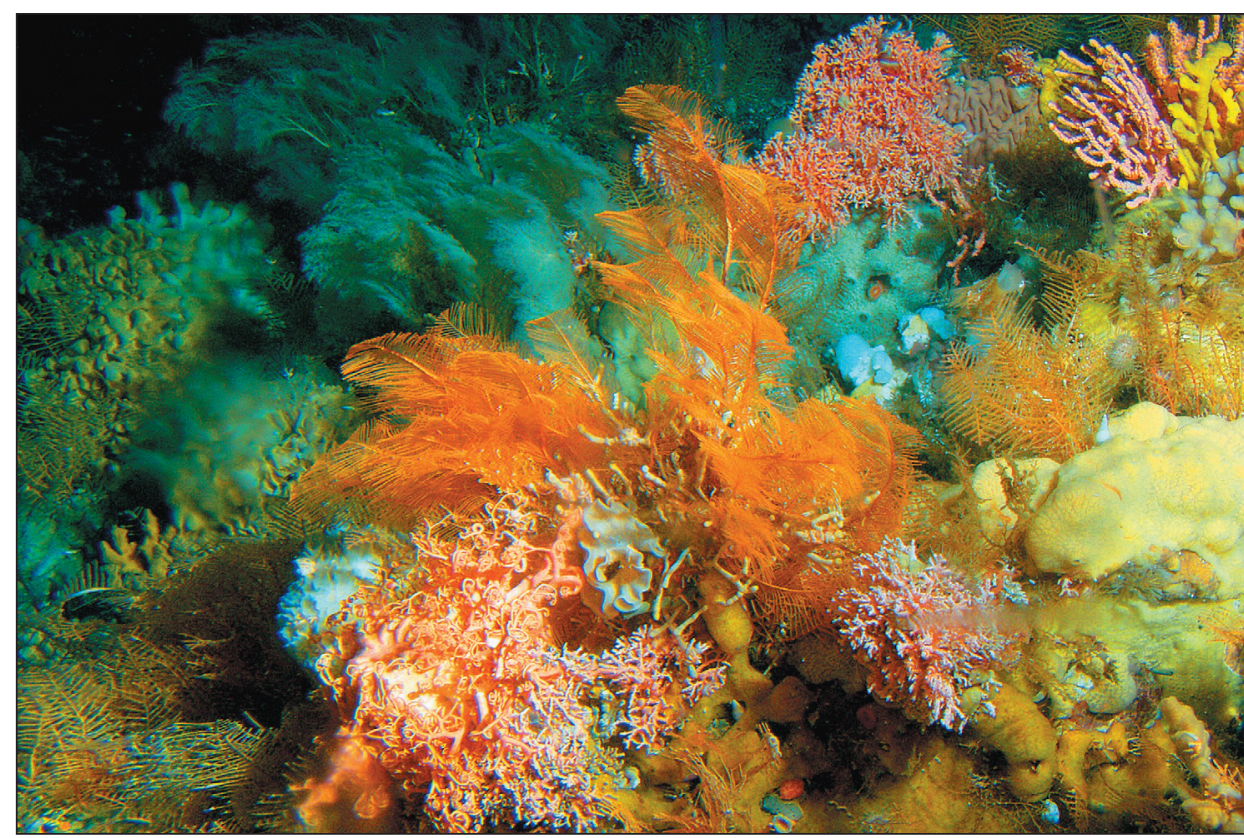

Figure 4. The colorful landscape and incredible diversity of a deep-sea reef in the Aleutian Islands. Photo credit: Alberto Lindner, NOAA Fisheries. physical changes like temperature, water flow, amount of UV, or other extrinsic factors? That is, are the changes in the microbial community indicators of certain types of stress?

(3) Can changes in the microbial community be used as "early warnings" of bleaching or disease? A few studies have shown that coral-associated bacterial communities change when the coral bleaches or becomes infected. Maybe that shift is

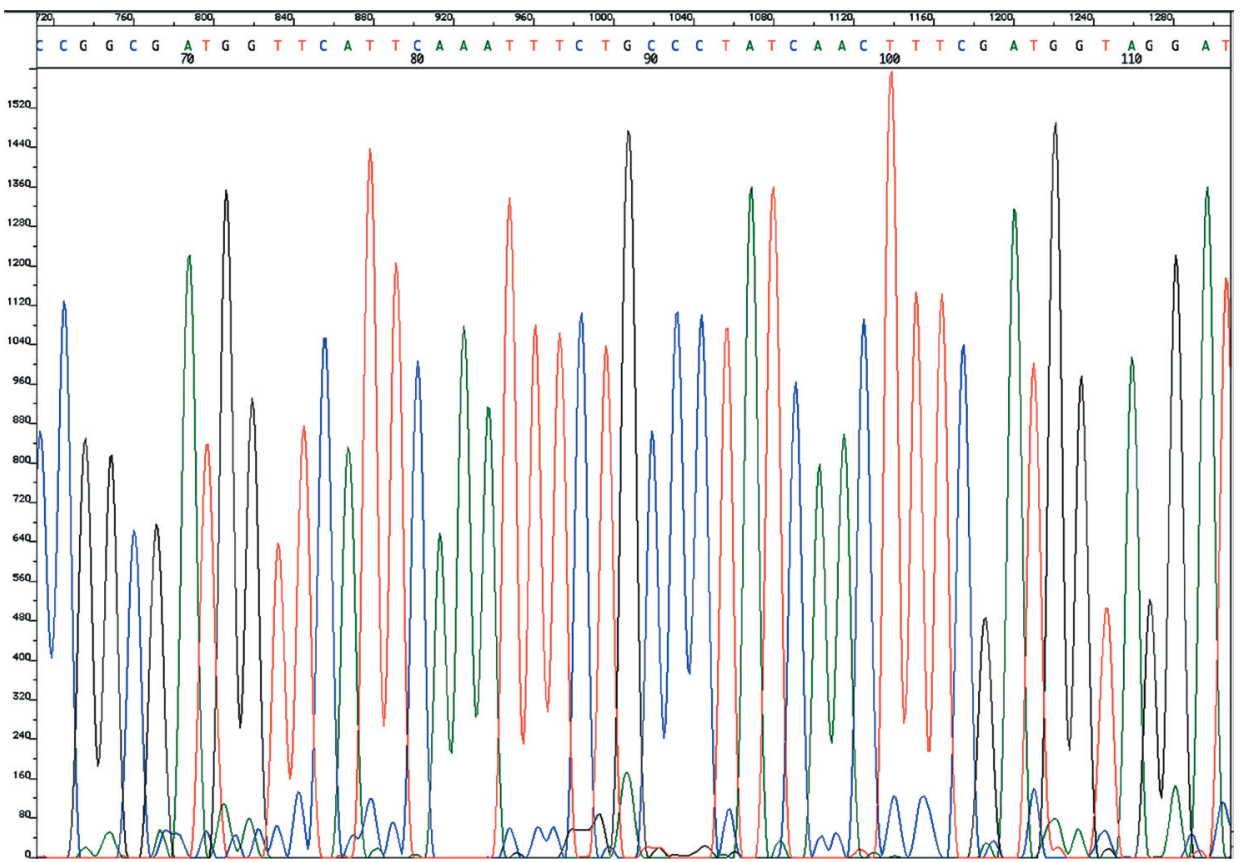

Figure 3. Sequencing means using a chemical reaction to determine the order of the four nucleotide bases $(A$, G, C, T) that make up DNA. Each "species" of microbe will have a unique combination of bases, sort of like a bar code. In this example of a DNA sequence chromatogram, each of the four nucleotide bases is coded in a different color. detectable before the macroscopic signs of distress are apparent in the coral.

(4) If microbes can be used as a diagnostic tool, can the samples be non-invasive, meaning only the mucus layer is sampled, not the coral tissue? There are different microbes in the thin layer of mucus covering corals and inside the coral tissue. If the microbial community in the mucus is responsive enough to the coral's metabolism, we may be able to test the mucus alone. Over the course of the larger study, corals under different stress conditions on the reef will be evaluated for acclimatization, adaptation, and (or) susceptibility to disease. The results of these investigations may play an important role in choosing the most effective Marine Protected Areas to mitigate the effects of global warming on coral communities.

\section{Discovering Archaea Associated With Corals [Christina Kellogg]}

Many studies have shown that coral mucus hosts a diverse bacterial community. Archaea (formerly called archaebacteria) are the third domain of life (Fig. 1). Superficially, they look like bacteria, but genetically and biochemically, they are very different. For years, archaea were found only in extreme environments, such as hot springs or deep-sea hydrothermal vents. More recent studies, however, have uncovered archaea in temperate coastal waters. Archaea have also been detected in marine sediment and as symbionts 


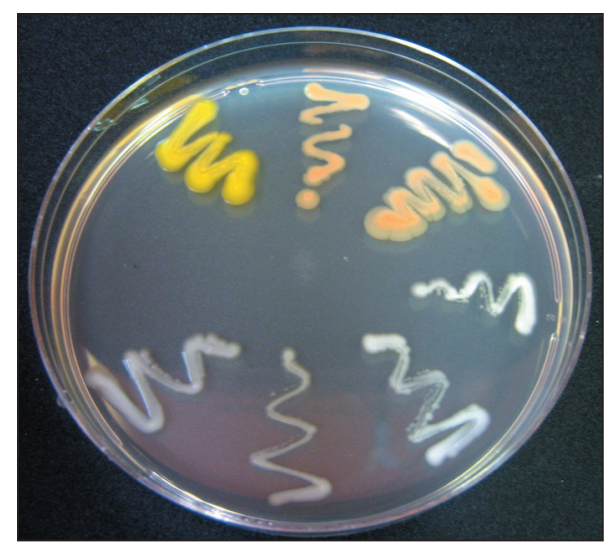

Figure 5. Bacteria, isolated from deep-sea corals, are grown on dishes of nutrient agar for identification and further study. Photo credit: Christina Kellogg, USGS.

in sponges. Archaea remain difficult to cultivate in the laboratory, so most current research is based on detection of archaeal DNA sequences, which are used to identify different types of archaea.

To determine if there were archaea associated with tropical corals, mucus was collected from three species of reefbuilding corals in the U.S. Virgin Islands: Montastraea annularis complex, Diploria strigosa, and Diploria labyrinthiformis. Total microbial DNA was extracted from the coral-mucus samples, purified, and analyzed by molecular techniques. The resulting archaeal DNA fragments were sequenced (Fig. 3) and identified by comparison to known sequences in GenBank, an international repository for sequence information. A diverse archaeal community was detected in each of the mucus samples. Most of the coral-associated archaeal sequences were most closely related to archaea previously detected in marine waters. The remaining sequences were similar to archaea detected in marine sediment and hydrothermal vents. A few sequences were distinctive enough to be considered novel. Unlike previous bacterial studies, which found specific associations between certain bacterial and coral species, this study found that archaea seem to be generalists, with the main types detected being observed in all three coral species tested. Finding archaea, with their varied (and, for the uncultivated specimens, mostly unknown) metabolic capabilities, adds to the likelihood of unique biogeochemical processes occurring in the microbial communities associated with corals. This work was done in cooperation with the Virgin Islands National Park and was published in the journal Marine Ecology Progress Series (Kellogg, 2004).

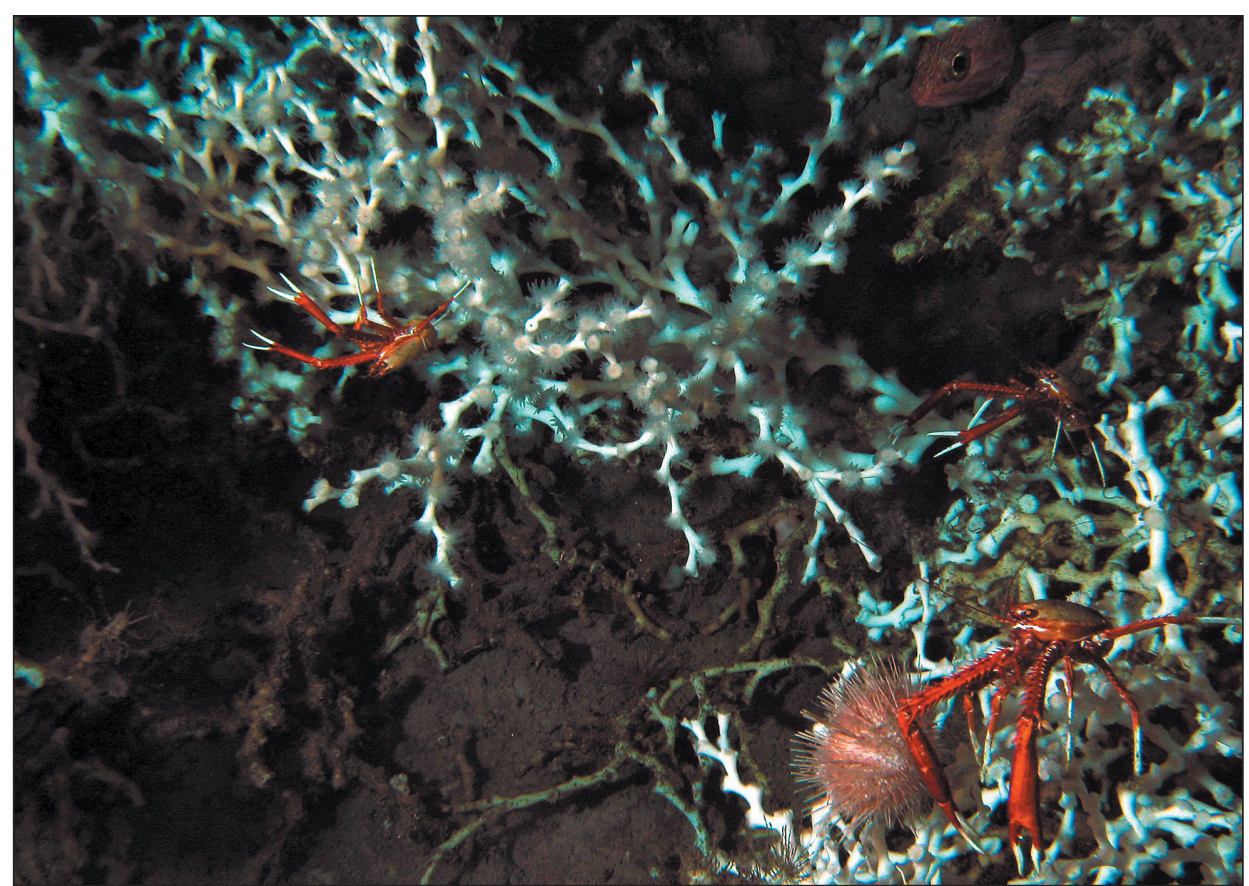

Figure 6. Lophelia coral in the Gulf of Mexico provides a complex habitat for many organisms, including the rosefish, squat lobsters, and sea urchin seen here. Photo credit: Christina Kellogg, USGS.

\section{Microbial Ecology of Deep-Sea Corals [Christina Kellogg]}

Most people are familiar with tropical coral reefs, located in warm, shallow waters. However, corals also exist hundreds and even thousands of meters below the ocean's surface where it is cold and completely dark (Fig. 4). In the last few decades, scientists have discovered and photographed incredible gardens of deep-sea corals off the coasts of North America, Great Britain, Europe, Scandinavia, Australia, and New Zealand. These corals survive without algal symbionts (because there is no light for photosynthesis) and may take a long time to grow. Thus the potential role of coral-associated microbes is even more interesting. It is possible that the microbes are helping to feed these corals, similar to the chemosynthetic bacterial symbionts that feed hydrothermal-vent worms. The microbial communities of these coldadapted corals are also likely to contain novel organisms, which will not only increase our understanding of microbial diversity but could also be a source of new enzymes or pharmaceuticals.

\section{3a. Study Site: Aleutian Islands}

The Aleutian Islands are a string of volcanic islands stretching from Alaska toward Russia, dividing the North Pacific from the Bering Sea. Since 2002, National Oceanic and Atmospheric Administration (NOAA) fisheries scientists from the Auke
Bay Laboratory have been documenting deep-water coral and sponge reefs in waters off these islands (Fig. 4). The deep-sea corals that make up the Aleutian reefs are mainly gorgonians (soft corals). The diversity and abundance rival those seen in tropical coral reefs. During a 2004 cooperative research cruise, three types of gorgonians were collected with the Delta submersible for microbial analysis. Live bacteria and fungi have been cultured from these samples (Fig. 5), and total microbial DNA was extracted so that molecular techniques could be employed to identify archaea and uncultured bacteria and fungi.

\section{3b. Study Site: Gulf of Mexico}

The deep-water coral Lophelia pertusa is globally distributed but is most common in the Atlantic Ocean. This hard branching

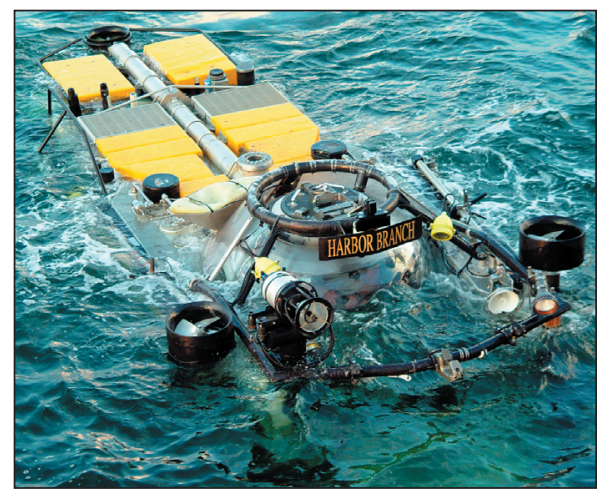

Figure 7. Submersibles, like Harbor Branch Oceanographic Institute's Johnson-Sea-Link, are essential to deep-sea coral collection missions. Photo credit: Cheryl Morrison, USGS. 
coral forms bushes or thickets that provide extensive reef habitat for fishes and invertebrates (Fig. 6). The USGS has partnered with the Minerals Management Service (MMS), NOAA, and the University of North Carolina to determine the biology and ecology of Lophelia reefs that have been discovered in the Gulf of Mexico. Using a submersible to collect samples and environmental data at depths to 800 meters (Fig. 7), USGS scientists are determining the relationship between Lophelia and the reef's microbial flora; Lophelia's genetics, growth, metabolism, and reproduction; and food-web relationships of reef-associated organisms through the analysis of stable isotopes. Many of these Lophelia clumps are located near natural hydrocarbon seeps in the ocean floor, so it is of particular interest to determine if hydrocarbon-utilizing microorganisms are the link between the coral and the seeps. Samples of Lophelia were collected for microbial experiments in the summer of 2004, and additional samples will be collected in 2005 .

\section{Microbial Wars: Mucus-Associated Bacteria Fend off Coral Pathogens [John Lisle]}

Most coral-disease pathogens that have been identified are bacteria (reviewed by Rosenberg and Loya, 2004; Richardson, 1998). Although some microbes have been successfully linked to specific coral diseases, the mechanisms by which they establish infections are not understood.

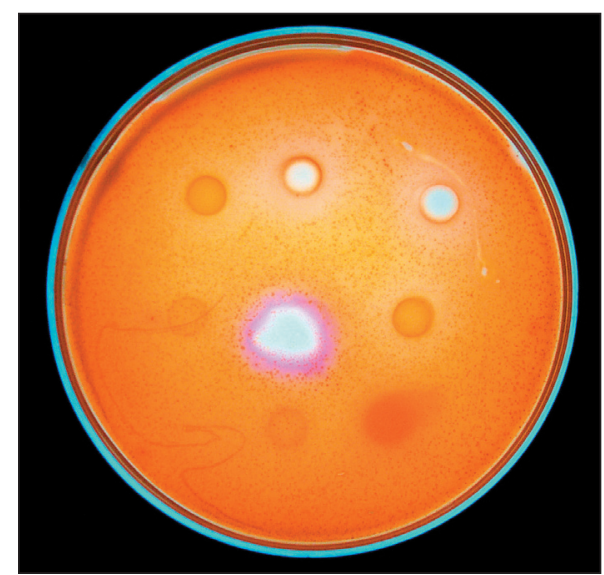

Figure 8. A bacterial-inhibition experiment. Serratia marcescens is spread over an agar plate (its growth is visible as a orange haze on the colorless agar); then native bacteria are spotted on top of it (visible as the circles on the plate). Native bacteria that do not resist $S$. marcescens are grown over (orange circles), but white circles indicate antibacterial activity. Those spots are colorless because the $S$. marcescens could not grow there. Photo credit: John Lisle, USGS.
One of the recent investigations of bacterially induced coral diseases concluded that a bacterium commonly found in aquatic environments and human feces, Serratia marcescens, is the cause of white-pox disease in the elkhorn coral Acropora palmata (Patterson, 2002). Previous studies that have isolated alleged coral disease-causing microbes from infected tissues have done so from the perspective of the pathogen being introduced from the sea water, with no consideration of the role played in the infection process by the native bacteria within the coral's mucus layer. This aspect is important to consider because the mucus layer provides a barrier between the water and coral tissues.

To determine if native bacteria living in coral mucus are capable of providing an anti-bacterial defense against outsider microbes, mucus samples were collected from healthy corals in the Florida Keys. Bacterial isolates recovered from these mucus samples were screened for antibacterial activity against a strain of $S$. marcescens (a known coral pathogen), and Escherichia coli (a bacterium commonly found in human feces). Approximately 5 percent of the screened isolates exhibited antibacterial activity, where inhibition of growth was the criterion (Fig. 8). These native bacterial isolates were characterized by biochemical tests and gene sequencing in collaboration with University of South Florida microbiologist Valerie J. Harwood. All of the isolates were identified as belonging to the genus Vibrio. These data indicate that coral-associated bacteria residing in the mucus layer provide a first line of defense against the establishment of potentially pathogenic bacteria in corals.

\section{CONCLUSION}

There is no doubt that we live in a microbial world. Bacteria, archaea, fungi, and algae participate in all the fundamental biogeochemical processes that allow life as we know it to exist. Coral microbial ecology is just beginning to address the importance of microbes to the health and function of coral reefs.

\section{REFERENCES}

Frias-Lopez, J., A.L. Zerkle, G.T. Bonheyo, and B.W. Fouke, 2002, Partitioning of bacterial communities between seawater and healthy, black band diseased, and dead coral surfaces. Applied and Environmental Microbiology, v. 68, p. 2214-2228.

Kellogg, C.A., 2004, Tropical Archaea: diversity associated with the surface microlayer of corals. Marine Ecology Progress Series, v. 273, p. 81-88.

Pantos, O., R.P. Cooney, M.D.A. Le Tissier, M.R. Barer, A.G. O’Donnell, and J.C. Bythell, 2003, The bacterial ecology of a plague-like disease affecting the Caribbean coral Montastrea annularis. Environmental Microbiology, v. 5, p. 370-382.

Patterson, K., J. Porter, K. Ritchie, S. Polson, E. Mueller, E. Peters, D. Santavy, and G. Smith, 2002, The etiology of white pox, a lethal disease of the Caribbean elkhorn coral, Acropora palmata. Proceedings of the National Academy of Sciences, USA, v. 99, p. 8725-8730.

Richardson, L. L., 1998, Coral diseases: what is really known? Trends in Ecology and Evolution, v. 13, p. 438-443.

Rohwer, F., V. Seguritan, F. Azam, and N. Knowlton, 2002, Diversity and distribution of coral-associated bacteria. Marine Ecology Progress Series, v. 243, p. 1-10.

Rosenberg, E. and Y. Loya, 2004, Coral Health and Disease. Springer-Verlag, Berlin, Germany, 488 p.

Wild, C., M. Huettel, A. Klueter, S.G. Kremb, M.Y.M. Rasheed, and B.B. Jørgensen, 2004, Coral mucus functions as an energy carrier and particle trap in the reef ecosystem. Nature, v. 428, p. 66-70.

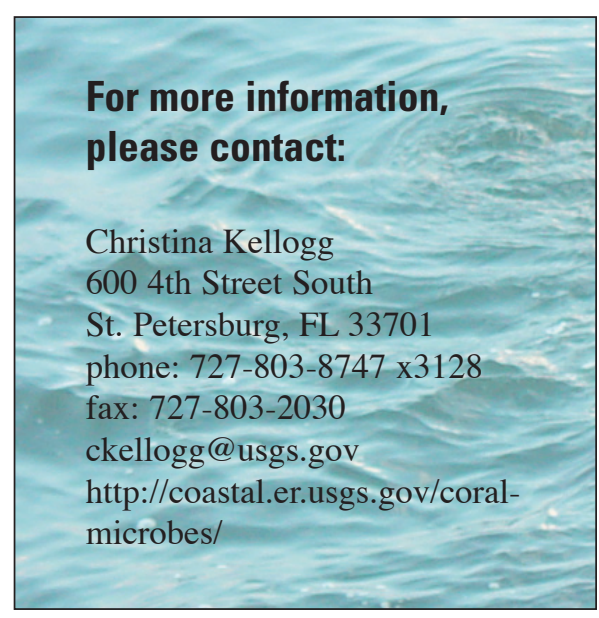

